\title{
Electrochemical Determination of Monocrotophos in Water and Fruits using acetylcholinesterase immobilized on CNTs modified Carbon paste electrode
}

\author{
Yunfeng Zhao ${ }^{1, *}$, Ruisheng Zheng ${ }^{2}$ \\ ${ }^{1}$ Analysis and Testing Center, Yancheng Institute of Technology, Yancheng, Jiangsu, 224051, China \\ ${ }^{2}$ College of Oceanology and Food Science, Quanzhou Normal University, Quanzhou, Fujian, 362002, \\ China \\ *E-mail: zhaoyunfeng1188@126.com
}

Received: 9 August 2021/ Accepted: 16 September 2021 / Published: 10 November 2021

\begin{abstract}
This study was conducted on the synthesis and electrochemical studies of immobilized acetylcholinesterase on chitosan and CNTs modified carbon paste electrode (AChE-CS/CNTs/CPE) for determination of monocrotophos (MCs) in water and fruits samples. For the preparation of the modified electrode, the functionalized CNTs were modified the CPE surface, and then AChE was immobilized through the mixture of AChE-CS on CNTs/CPE surface. Morphological analysis of modified electrodes using SEM showed that CNTs were homogeneously covered the CPE that forms a net-like film, resulting in the facilitation fixing of the AChE-CS onto the surface of GCE. The result of electrochemical studies using CV and DPV experiments indicated that the AChE-CS/CNTs/CPE can act as high stable, wide linear range and selective MCs sensor because of a combination of chitosan polymer and AChE, and high porous and more defect on functionalized CNTs as a nanostructured substrate which provides many electroactive sites on AChE-CS/CNTs/CPE. The sensitivity, linear range and limit of detection of the sensor were estimated $0.9038 \mu \mathrm{A} / \mu \mathrm{M}, 1$ to $70 \mu \mathrm{M}$ and $0.3 \mathrm{nM}$, respectively. The practical application of AChE-CS/CNTs/CPE to the determination of MCs in prepared real samples of strawberry and agricultural wastewater was investigated and analytical results showed the acceptable values for recovery (98.70 to $99.77 \%$ ) and RSD (1.77 to $4.08 \%$ ). These results indicated a good accuracy of the proposed method for MCs detection in fruits and water samples.
\end{abstract}

Keywords: Acetylcholinesterase; Chitosan, Functionalized CNTs; Determination of monocrotophos; Differential pulse voltammetry

\section{$\underline{\text { FULL TEXT }}$}

(C) 2021 The Authors. Published by ESG (www.electrochemsci.org). This article is an open access article distributed under the terms and conditions of the Creative Commons Attribution license (http://creativecommons.org/licenses/by/4.0/). 